\title{
Students' Attitudes towards Information Technology and the Relationship with their Academic Achievement
}

\author{
Zhwan Dalshad Abdullah \\ Universiti Sains Malaysia, Malaysia \\ Azidah Bit Abu Ziden \\ Universiti Sains Malaysia, Malaysia \\ Rahimi Binti Chi Aman \\ Universiti Sains Malaysia, Malaysia \\ Khalid Ismail Mustafa \\ Koya University, Iraq
}

\begin{abstract}
The present quantitative study aims to find out the underlying factors of attitudes towards information technology and the relationship with academic achievement among students, through a self-developed questionnaire. The attitudes of the respondents were assessed in terms of three dimensions; namely affection, behavior, and belief. The results revealed a statistically significant difference between Arts and Science students in terms of their attitude towards IT in favor of Science students, and also proved that there was no statistically significant correlation between students' academic achievement and their attitudes towards IT. While students at the medium level of academic achievement tended to score higher on the affection toward IT comparing with students at the satisfactory level of the academic achievement. The results of this study provide information for policy makers, and the researchers who are interested in understanding the factors that affect technology use by students in their learning.
\end{abstract}

Keywords: Student attitudes; Information technology; Academic achievement; Students' disciplines

\section{Introduction}

Information technology (IT) refers to the hardware and software used in computerized information systems and has been a major force in shaping the current society (Bawaneh, 2011; Safdar et al., 2012). It is obvious that the revolution of information technology has changed the face of the world and had led to the development in all fields (Ali, 2012). Technology is pervasive, and it is invading every corner of the world, albeit some areas more slowly than others. In these areas, there is an apparent disparity in the utilization of technology, primarily owing to reasons of cost or lack of services in the area (Kompf, 2005). However, Iraq is of an underdeveloped country 
in the field of technology use and it might be due to the risks and high costs (Jarrah \& Ashour, 2009; Muslim, 2010; Samarrai \& Rais, 2006). Additionally, Al Bataineh and Anderson (2015) stated that schools in poor countries such as Jordan and Egypt lack an appropriate level of technology (e.g., not enough computers), based on this statement there are several other Arab countries facing the same problem of lacking technology in schools and universities. However, there is a need for educators to understand students' attitudes toward the use of different types of technology as well as how these attitudes are related to their learning style (Jarrah \& Ashour, 2009; Yusuf \& Balogun, 2011). Liu, Lee, and Chen (2013) stated that attitudes are learned, and as such, are closely related to one's experiences in the process of learning. They concluded that, attitude can be defined as the outward manifestation of an individual's evaluation of an entity, based on previous knowledge and beliefs.

Furthermore, students' achievement is one of the key contributing factors determining the student's success in various subjects and areas (Shukakidze, 2013). As such, the academic achievement is the major aim of the field of education and the higher education systems. Educators are looking for ways of enhancing education and achieving desirable student outcomes (Eret, Gokmenoglu, \& Demir, 2013). Lei (2010) stated that the generous investments were supported by the strongly held premise that technology can help students learn more efficiently and effectively, and as a result increase student academic achievement. The belief of connection between technology and student achievement is a theme commonly emphasized in mission statements of educational technology projects and arguments to support educational technology investment. In fact, technology becoming a more prevalent part of the education culture with each passing year (Lukow, 2005), the integration of technology into education systems is forcing colleges and universities to make dramatic changes, by increasing the quality, diversity and availability of information, and altering the teacher-student relationship (Inoue, 2007).

Technology impacts students' daily lives and certainly plays an important part in developing students' positive and negative attitudes (Volk, Yip, \& Lo, 2003). The lack of computers in Iraqi classrooms has led most of the students to become unfamiliar with using them and to have low behavioral attitudes toward using computers (Muslim, 2010). Hence, there is a need to look at students' attitudes toward information technology whether negatively or positively. If attitude influences the use of information technology in their daily lives or whether is it used to get information or just for entertainment. The Regional Ministry of Higher Education in Kurdistan Region of Iraq has actively encouraged lecturers to integrate technology into the curriculum especially the Microsoft PowerPoint presentation which every lecturer has required using it to improve the quality of teaching and learning process. Despite employing modern technology such as computers and projector (LCD) in universities in Iraq, it would not exceed a means to display the content of the same conventional approach, which leads to the low level of academic achievement and in particularly in recent years (Juma \& Ahmad, 2012).

For these reasons, the current study attempts to examine students' attitude towards IT and to indicate whether there is a significant difference between science and art students in terms of their attitude towards IT on one hand and the relationship with their low academic achievement on the other hand. Allport (1954) pointed out that attitude involved particular responses like cognition, behavioral and affective responses having clear and specific associations with attitude object. Attitude in this study refers to three components, such as affection, behavior, and 
cognition. Huskinson and Haddock (2006) stated that affection refers to feelings of an individual associated with an attitude object, cognition refers to individual beliefs or attributes associated with an attitude object, and behavior refers to past behavior or behavioral intentions relevant to an attitude object.

The previous studies conducted on this topic can be categorized into two categories. The first category of studies addressed the students' attitudes towards IT by integrating IT in classroom and comparing students' scores before and after IT integration, such as Tingoy and Gulluoglu (2011), they indicated that students' initial dislike toward IT was greatly reduced at the end of the IT course. In their study Wong and Hanafi (2007), have found improved attitudes toward IT usage in both females and males after the exposure to IT. Muslim (2010) has examined students' attitudes toward using computers in learning; the findings reported that, though the students' high emotional and cognitive attitudes, their behavioral attitude were low before the experiment started. However, the results showed that the cognitive, emotional and behavioral attitudes scores increased significantly after the students' exposure to computer use. In contrast, a study conducted by Shunnaq and Domi (2010) in Jordan regarding students' attitude towards e-learning found significant differences between students in the control and in experimental groups in terms of attitude toward using e-learning in class which was negative, the experimental group held a positive attitude before employing e-learning in class and their attitude changed to negative after employing e-learning in class. Regarding the second category of studies, focusing on the students' attitudes towards the use of IT in their learning by surveying students to find out whether they hold positive or negative attitudes such as (Al-Harby, 2012; Tuncer, Dogan \&Tanas, 2013; Yalman \& Tunga, 2014; Yusuf \& Balogun, 2011). In their studies, they indicated that students have positive attitudes towards the use of IT in their learning.

There was a few studies found examining the difference between arts and science students in terms of their attitude towards IT such, (Abdulhamed, 2005; Abul-Ela \& Shezawi, 2004; Subramani, 2012) they found that there was a statistically significant difference between Arts and Science students in their attitude towards IT, in favor of Science students. Meanwhile, Abedalaziz, Jamaluddin, and Leng (2013) have measured the postgraduate students' attitudes toward the Internet and the computer in Malaysia. The result found no significant differences between participants' attitudes toward the Internet and computer related with field of study.

Many studies have been conducted indicating the students' attitudes towards IT and the influences on academic achievement. The analysis of the previous literature was found to have mixed results regarding the relationship between students' attitudes towards IT and their academic achievement. Studies indicated a significant relationship between students' attitudes towards IT and their academic achievement (Juma \& Ahmed, 2012; Schroeder et al. 2007; Taylor \& Duran, 2006). Ilgan (2013), found the academic achievements and student's attitudes are closely related. He pointed out that it is necessary to improve attitudes to increase student's academic achievement. In addition, Skryabin, Zhang, Liu, \& Zhang (2015) found out that the national ICT development level is a significant positive predictor for students' academic performance. Previous study conducted by Akpinar et al. (2009) explored the relationships between students' attitudes toward science and technology and academic achievement. They found significant positive correlations between attitudes toward science and technology and their academic achievement. While, in their study Shieh, Chang, and Liu (2011) concluded that the implementation of the 
technology tools alone may not be sufficient to improve students' performance and achievement. Lei (2010) suggested that even though technology use showed a significant positive association with students' learning habits, these technology uses had no significant influence on their academic outcomes, as well as, Aljabri (2012) reported that students use all the applications in the same way and there is more use of social networking programs such as Google translator, YouTube, Facebook, MSN, e-mail and mobile, but no significant correlation between the level of use of application software and students' academic achievements were found.

\section{Methodology}

\section{Purpose of Study}

With technology advancing at an increasing rate, it is necessary to understand how it shapes or influences the learning process. As an ever-present component in higher education pedagogy, more empirical evidence is needed to demonstrate the connections between students' preferences for learning and the use of this technology (Kompf, 2005). This study contributes to a better understanding of technology usage, attitudes, and the academic achievement level among students at the universities in Iraq. Therefore, this study would provide insights into the nature of the attitudes toward IT of the students and the relationship with their academic achievements which can explain their eventual success or failure. The confirmation of this relationship highlights the need for early intervention plans geared towards ensuring positive attitudes among the students and improving their level of academic achievement.

Generally, this study aimed to concentrate on students' attitudes regarding IT and the relationship with their academic achievement according to the disciplines. Specifically, the study examined the underlying dimensions of attitudes towards IT, concerning the field of study Arts and Science, and to determine the relationship with the academic achievement

\section{Research Questions}

In this study the following research questions were examined:

RQ1: What are the underlying dimensions of attitude towards IT?

RQ2: What are the Science and Art students' attitudes toward IT? Is there any significant difference between Science and Art students' attitudes toward IT?

RQ3: Is there a significant relationship between students' attitudes toward IT and their academic achievement?

\section{Research Design}

This study used a quantitative approach with a survey design. The data collection instrument was developed by the researcher in order to examine the undergraduate students' attitudes towards 
IT. It consists of 44 items using a Likert scale from 1 (strongly disagree) to 5(strongly agree), and three hypothesized dimensions (affections, intentional behavior, and belief) to underlying the students' attitudes toward IT. The affection toward IT represents the feelings of individuals regarding $\mathrm{IT}$, which is used to measure how much the students liked using the computers and the Internet. The behavior component represents the students' intention, and participation to use IT, while, the cognition component refers to the beliefs of an individual regarding the use of IT. This research utilized established literature such as (Christensen \& Knezek, 1998; Mustafa, 2005; Rob, Mary, \& Grainne, 2012; Wong \& Hanafi, 2007; Yusuf \& Balogun, 2011) to develop the attitude toward IT questionnaire by modifying, changing and adding the items to be relevant in measuring the three attitude components.

In addition, the 5-point Likert scale is used for all items. The questionnaire was validated by specialists and experts. The questionnaire was pilot tested on a broad sample $(\mathrm{N}=300)$ at Koya University. The Principal Component Analysis PCA technique was applied to decide the number of attitude dimensions. As a result, 24 items were reduced from the attitude toward IT questionnaire, due to low corrected item-total correlation values and the problematic items; therefore they have not been used for the main study. Consequently, only 18 items were retained for the three dimensions of attitude toward IT questionnaire. The reliability for the 18 items was established at .74 for affection toward IT ( 6 items), .82 for intentional behavior toward IT (5 items), and .84 for belief toward IT (7 items) using the Cronbach alpha, indicating good internal consistency.

\section{Overview of Sample}

The study was conducted at Koya University in Iraq. From the population of 3534 undergraduate students in Faculty of Science \& Health, Faculty of Engineering, Faculty of Humanity \& Social Science, and Faculty of Education, according to the proportional stratified random sampling technique, the research identified two subgroups; Science $1548(43.80 \%)$ of the population and Art 1986 (56.20 \%) of the population. The respondents were selected from the second and fourth year Arts and Science undergraduate classes as a study sample. The reason for selecting these two stages was to know the overall grades of students' academic achievement in all study materials in their last year study exams. The sample size that has been chosen in this study was consisting of 800 students. These 800 students were divided into two subgroups based upon the same percentages of Science and Arts students in the population of the study, which was $(43.80 \%) 350$ students for the Science, and (56.20\%) 450 students for the Arts field representing the sample size of the study. According to Gay and Airasian (2003), if the population size is around 5,000; the sample size of 400 will be adequate.

\section{Research Procedures and Data analysis}

The questionnaire was distributed to 800 students at Koya University, which 678 questionnaires were valid (84.75\%), including 333 Art field students (49.2\%) and 345 Science field students (50.8 \%). For data analysis; the Principal Component Analysis (PCA) technique was applied to examine the construct of students' attitudes toward information technology based on the data collected from the respondents $(n=678)$ which was measured by 18 items. Furthermore, the Descriptive 
Statistics, Independent-Samples t-Test, and Pearson correlation were also performed to answer the research questions.

\section{Descriptive Summary of Student's Academic Achievement and Disciplines}

After collecting the data, only 678 survey instruments were fully completed by the participants. The response rate calculated for this survey instrument was $84.75 \%$. Table 1 presents the respondents' characteristics, frequencies and the percentages based on the demographic information. The field of the study was divided into two subcategories of Art and Science, and in relation to this, Table 1 reveals that $50.8 \%$ of the students were from the Science field and $49.2 \%$ of them were from the Art field.

In addition, it established that students' academic achievement at Koya University is low. Based on Table 1, the academic achievement of the majority of students (42.0\%) was between $50-59$ points which were rated as 'satisfactory' level, as an overall academic achievement of the study year which considered as the lowest level.

Table 1. Distribution of Sample According to Demographic Variable

\begin{tabular}{llcc}
\hline Variables & Characteristic & Frequency & $\%$ \\
\hline Field of Study & Art & 335 & 49.2 \\
& Science & 346 & 50.8 \\
& & & \\
Academic Achievement & 49- less Fail & 8 & 1.2 \\
& 50-59 Satisfactory & 286 & 42.0 \\
& 60-69 medium & 257 & 37.7 \\
& 70-79 good & 97 & 14.2 \\
& 80-89 V. good & 28 & 4.1 \\
& 90-99 excellent & 5 & 0.7 \\
\hline
\end{tabular}

\section{Results}

To answer the first research question: What are the underlying dimensions of attitudes toward IT? Table 2 presents the correlation matrix and the descriptive statistics of the attitudes toward the IT items. The degree of inter-correlation among these variables justifies the use of PCA. The KaierMeyer-Olkin measure of sampling adequacy among the variables was very high .847 which is well above the recommended threshold of .6 (Kaiser, 1974) and the Bartlett's Test of Sphericity (2693.13) had reached statistical significance $(p=0.000)$ indicating that the correlations were sufficiently large. To obtain sufficient factor solution, the varimax rotation method was applied to the relevant data. 
Table 2. Correlations Matrix and Descriptive Statistics of Attitudes toward IT

\begin{tabular}{clllllllllllll}
\hline Item &. $\mathbf{1}$ &. $\mathbf{2}$ & $\mathbf{. 3}$ & $\mathbf{. 4}$ & $\mathbf{. 5}$ & $\mathbf{. 6}$ & $\mathbf{. 7}$ & $\mathbf{. 8}$ & $\mathbf{. 9}$ & $\mathbf{. 1 0}$ & $\mathbf{. 1 1}$ & $\mathbf{. 1 2}$ & $\mathbf{. 1 3}$ \\
\hline Item 1 & & & & & & & & & & & & & \\
Item 2 & .485 & & & & & & & & & & & \\
Item 3 & .419 & .406 & & & & & & & & & & \\
Item 4 & .218 & .255 & .276 & & & & & & & & & \\
Item 5 & .241 & .215 & .324 & .650 & & & & & & & & \\
Item 6 & .242 & .156 & .363 & .432 & .508 & & & & & & & \\
Item 7 & .201 & .291 & .197 & .353 & .369 & .296 & & & & & & \\
Item 8 & .189 & .179 & .285 & .375 & .426 & .402 & .328 & & & & & \\
Item 9 & .146 & .170 & .179 & .236 & .182 & .245 & .196 & .308 & & & & \\
Item 10 & .212 & .220 & .213 & .328 & .296 & .226 & .222 & .261 & .429 & & & \\
Item 11 & .148 & .297 & .199 & .368 & .311 & .244 & .305 & .231 & .295 & .487 & & & \\
Item 12 & .164 & .211 & .198 & .272 & .244 & .225 & .225 & .193 & .313 & .577 & .644 & & \\
Item 13 & .182 & .183 & .238 & .384 & .423 & .270 & .322 & .320 & .174 & .217 & .268 & .218 & \\
& & & & & & & & & & & & & \\
Mean & 3.58 & 3.63 & 3.73 & 4.43 & 4.50 & 4.07 & 4.20 & 4.02 & 3.14 & 3.25 & 3.69 & 3.48 & 4.55 \\
SD & .989 & 1.049 & 1.016 & .833 & .747 & .953 & .956 & .924 & 1.184 & 1.130 & 1.103 & 1.149 & .715 \\
\hline
\end{tabular}

The attitude toward the IT construct is hypothesized as a three-dimensional construct underlying student's attitude toward any task they have to do using the computer. The response to 18 items was subjected to the varimax rotated PCA as a test of the construct validity. After this analysis, only 13 items were retained in Table 3.

The results suggest the existence of three common elements of the students' attitudes toward IT; namely students' affection toward IT, behavior toward IT, and belief (cognition) toward IT. In other words, these items measured the extent to which attitude have three inter-correlated dimensions, the visual inspection of the scree plot shown in Figure 1 supported the rotation of the three dimensions.

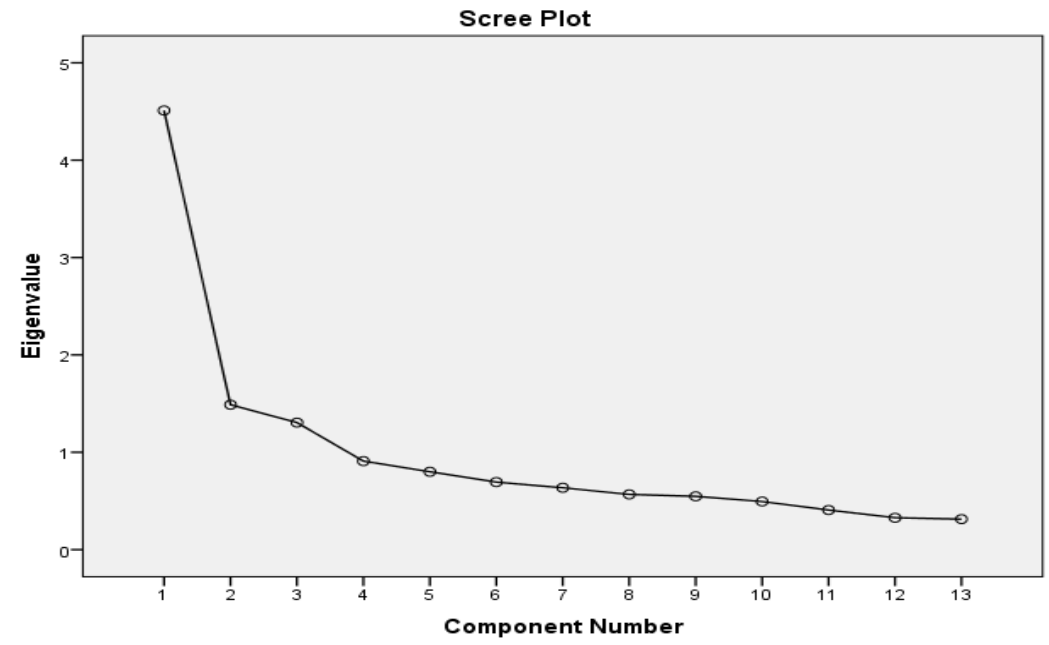

Figure 1. The Scree Plot of Attitude towards IT 
The empirical grouping of the items loaded on this factor reasons that the high scores on these dimensions imply that the students' attitudes toward IT are highly correlated with the positive feeling about it, high behavior to use it and high positive belief about it at Koya University. These 13-items' strong and significant loading on the three dimensions are represented as being initially hypothesized as an attitude toward IT. The analysis confined to three dimensions has met the above criteria that explained a total of $56.18 \%$ of the variance. The variance of the first dimension was (34.6\%), the second (11.4\%), and the last (10.0\%). The largest eigenvalue was 4.51 for the first dimension, while the other subsequent eigenvalues were 1.48 , and 1.30 , respectively.

Three estimated dimension loadings were large enough to be statistically significant $(p<.001)$. The loadings for the three dimensions were between .843 (for item 13 "I learn more from IT than I do from books") and .518 (for item 6 "I like to setup my email account myself"). In addition, the analysis produced loadings, all of which were in the same positive direction, and the solution was free from any noises such as factorial complexity and variable-specific factor, extracted positive loadings. This result has justified that the factor solution was extracted from the non-chance loading (Table 3).

Table 3. Loading for Three Factor Rotated Solution of Attitudes toward the Information Technology and the Cronbach's Alpha Coefficient

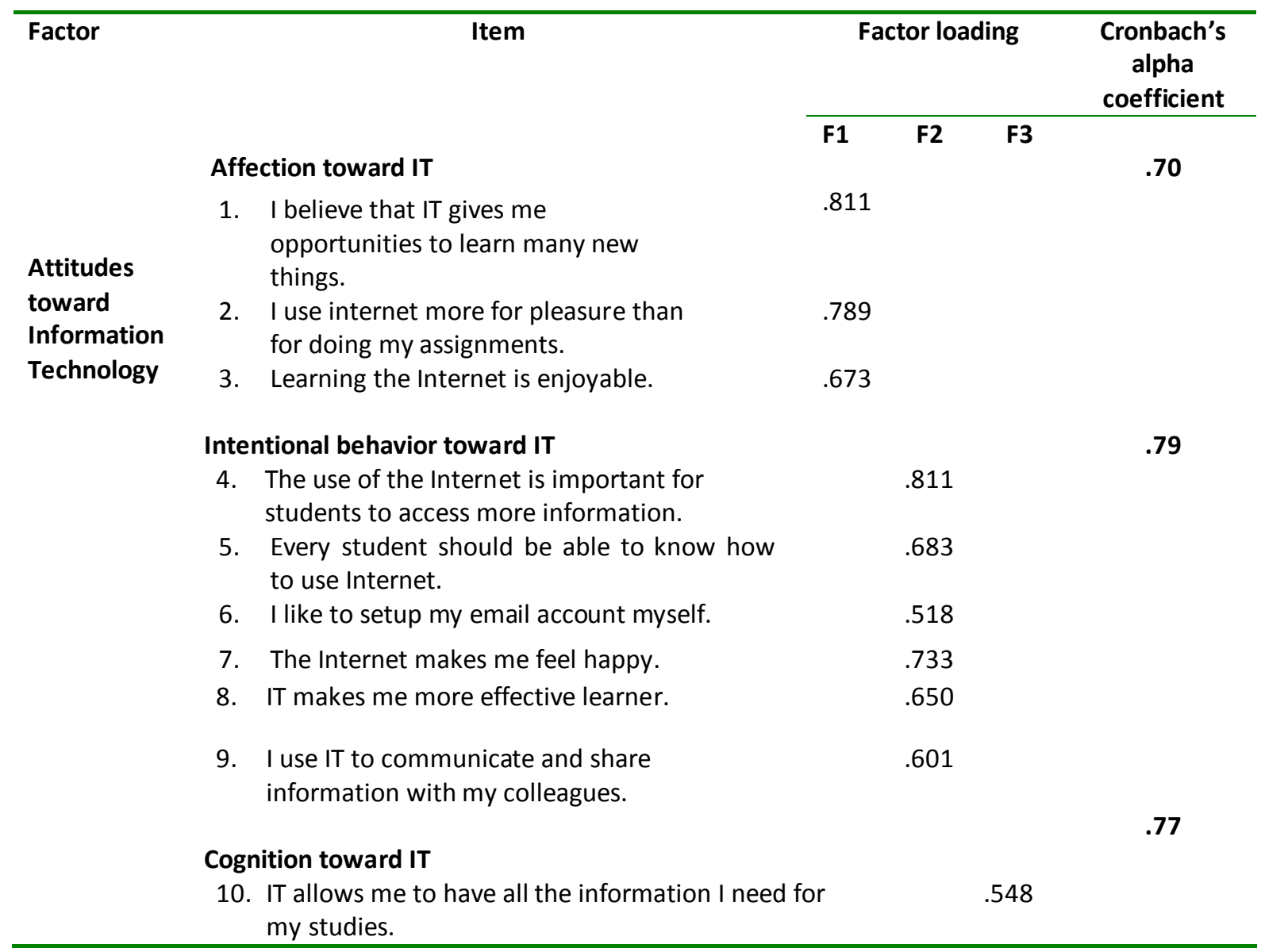


11. I believe that IT makes the study activities more interesting.

12. IT gives me control over things I want to do in my studies.

13. I learn more from IT than I do from books.

Overall Alpha

$\%$ of variance

$\mathbf{F 1}=34.6 \%$

4.51

$56.18 \%$

Eigenvalue

Total variance explained is

.781

.722

.843

Based on Table 3, the first dimension contains three items and it appears to be evaluative items. The variable loadings on the first factor relates to the affection toward IT which is used to measure how much the students liked using the computers and the Internet. The high score on this dimension suggests that the students have a positive feeling toward IT. Thus, the first dimension of the rotated factor appears to be related to students' emotions toward IT. The second dimension of the rotated factor significant loadings is on six items. Each item indicates the existence of one element of attitudes toward IT. Finally, the third dimension of the rotated factor significant loadings encompasses four items and each item indicates the existence of one element of attitudes toward IT; these four items represent a cognition component. In order to estimate the reliability for the three dimensions of the attitudes toward IT, Cronbach's alpha formula was used; see Table 3. The internal consistency indices for this scale were 0.70 for affection toward IT, 0.79 for intentional behavior toward IT, and 0.77 for belief toward IT. The overall Cronbach's alpha for this scale was $\mathbf{0 . 8 4}$. The varimax rotation indicates that three dimensions of the attitudes toward IT were moderately correlated.

Table 4. Descriptive Statistics of Scores on the Three Components of the Attitude toward IT Scale

\begin{tabular}{|c|c|c|c|c|c|c|c|}
\hline \multirow[t]{2}{*}{ Dimension } & \multirow[t]{2}{*}{$\underline{\mathbf{N}}$} & \multirow[t]{2}{*}{ Mean } & \multirow[t]{2}{*}{ SD } & \multicolumn{2}{|c|}{ Range } & \multirow[t]{2}{*}{ Skewness } & \multirow[t]{2}{*}{ Kurtosis } \\
\hline & & & & Minimum & Maximum & & \\
\hline Affection toward IT & 678 & 10.9351 & 2.41216 & 3 & 15 & -.291 & .259 \\
\hline Behaviour toward IT & 678 & 25.7640 & 3.58691 & 6 & 30 & -1.352 & 3.010 \\
\hline Belief toward IT & 677 & 13.5539 & 3.51145 & 4 & 20 & -.285 & -.158 \\
\hline
\end{tabular}

Table 4, displays the descriptive statistics and the normality testing values for the Attitude toward IT dimensions. From the data analysis, based on the mean score of attitude toward IT, students' behavior toward information technology appeared to be higher than their affection and belief toward IT. Moreover, students' affection toward IT appeared to be lower than their behavior, and belief toward IT.

Answers the second research question: What are the Science and Art students' attitudes toward IT? and Is there any significant difference between Science and Art students' attitudes toward IT? are presented in the following tables. The findings of the independent sample t-test for the Art and Science students in their attitude towards IT establish that the difference of the mean score 
for Art students $(M=49.51, S D=8.00)$, and the mean score for Science students $(M=50.96$, $S D=6.81)$, was statistically significant $(t(65)=-2.537, p=0.01),(p<0.05)$, Table 5 . This means that both groups held a positive attitude toward IT, but there was a statistically significant difference between Art and Science students in favor of Science students.

In other words, the result showed that there is no significant difference between Art and Science students in terms of their affection toward IT, the independent sample t-test reveals that the difference of $(t(67)=-872, p=0.38)$ between the two groups' means was found not to be statistically significant $(p>0.05)$, where the mean score for Art students was $(M=10.85, S D=2.49)$ and the mean score for Science students was $(M=11.01, S D=2.33)$, Table 4. Regarding the differences between Art and Science students in terms of their behavior toward IT, the mean score for the students in the Art field was $(M=25.35, S D=3.86)$ and the Science field was $(M=26.16$, $\mathrm{SD}=3.24)$. The t-test analysis indicates that the difference between Science and Art students in their behavior toward IT ( $t(64)=-2.951, p=0.00)$ was found to be statistically significant $(p<0.05)$ in favor of Science students.

Furthermore, the independent sample t-test reveals that students' belief (cognition) toward IT did not reach the statistical significance $(t(67)=-1.764, p=0.07)$. The differences between the mean scores of the students in the Art field $(M=13.31, S D=3.57)$ and the students in the Science field $(M=13.78, S D=3.43)$ indicate that the difference between the two groups' means was not significant $(p>0.05)$. This suggests that both Art and Science students have almost equal belief towards IT.

Table 5. The Result of the t-Test for Differences in Attitude toward IT components between Art and Science Students

\begin{tabular}{lllllllc}
\hline \multicolumn{1}{c}{ Variable } & Group & $\mathbf{N}$ & $\mathbf{M}$ & $\mathbf{S D}$ & $\mathbf{T}$ & $\mathbf{d f}$ & Sig \\
\hline Attitude toward IT & Art & 333 & 49.5165 & 8.00210 & -2.537 & 65 & 0.01 \\
& Science & 344 & 50.9680 & 6.81805 & & & \\
Affection toward IT & Art & 333 & 10.8529 & 2.49445 & -.87 & 67 & 0.38 \\
& Science & 345 & 11.0145 & 2.33086 & & & \\
Behaviour toward IT & Art & 333 & 25.3514 & 3.86749 & -2.951 & 64 & 0.00 \\
& Science & 345 & 26.1623 & 3.24974 & & & \\
Cognation toward IT & Art & 333 & 13.3123 & 3.57767 & -1.764 & 67 & 0.07 \\
& Science & 344 & 13.7878 & 3.43516 & & & \\
\hline
\end{tabular}

The next pursuit is to answer the third research question: Is there any significant relationship between students' attitudes toward IT and their academic achievement? This research question was tested by computing the Pearson correlations between the attitude toward IT scales and achievement, shown in Table 6. Based on Table 6, the total attitude toward the IT scale was not correlated with students' academic achievement, $(r=-.007, p>0.05)$. This was followed by students' academic achievement and their affection toward IT scores, $(r=.047, p>0.05)$. Similar results had been uncovered regarding the correlation between students' behaviour toward IT and their academic achievement $(r=-.032, p>0.05)$; as were scores on the belief toward IT scale, $(r=-$ $.014, p>0.05$ ). Thus, students with high or low attitude do not tend to have high or low scores on the academic achievement. 
Table 6. Correlation between Academic Achievements (Level and Grade) and Attitude toward IT

\begin{tabular}{lcccc}
\hline \multicolumn{1}{c}{ Attitudes } & $\mathbf{n}$ & Achievement & $\mathbf{r}$ & $\mathbf{p}$ \\
\hline Attitude toward IT & 677 & Level & -.007 & .865 \\
& & Grade & -.018 & .640 \\
Affection toward IT & \multirow{2}{*}{678} & Level & .047 & .218 \\
& & Grade & .016 & .684 \\
Behaviour toward IT & \multirow{2}{*}{678} & Level & -.032 & .401 \\
& & Grade & -.034 & .372 \\
Cognition toward IT & \multirow{2}{*}{677} & Level & -.014 & .716 \\
& & Grade & -.014 & .727 \\
\hline
\end{tabular}

Nevertheless, even though no correlations were found between the attitude toward IT and academic achievement, a set of independent samples t-tests were performed comparing the satisfactory (50-59) and medium (60-69)) level and grades of the students' academic achievement on the attitude toward IT scale, with the results shown in Table 7.

Table 7. The Result of the t-Test for Differences between Students Academic Achievement Satisfactory (50-59) and Medium (60-69) in Their Attitude towards IT Scale

\begin{tabular}{lllccccc}
\hline \multicolumn{1}{c}{ Variable } & \multicolumn{1}{c}{ Group } & N & M & SD & T & df & Sig \\
\hline Affection toward IT & Satisfactory (50-59) & 286 & 10.7063 & 2.42887 & -2.391 & 53 & 0.01 \\
& Medium (60-69) & 255 & 11.1922 & 2.29651 & & & \\
Behaviour toward IT & Satisfactory (50-59) & 286 & 25.9231 & 3.77169 & .606 & 53 & 0.54 \\
& Medium (60-69) & 255 & 25.7373 & 3.30676 & & & \\
Cognation toward IT & Satisfactory (50-59) & 286 & 13.5699 & 3.68406 & .296 & 53 & 0.76 \\
& Medium (60-69) & 254 & 13.4803 & 3.30373 & & & \\
\hline
\end{tabular}

As shown in Table 7, only one test produced statistically significant results; students in medium level of academic achievement had demonstrated higher affection toward IT scores, $(M=11.19$, $S D=2.29)$ than students at the satisfactory level of the academic achievement, $(M=10.70, S D=2.42)$. Thus, whilst students at the medium level of academic achievement tended to score higher on the affection toward IT scales ( $t(680)=-2.391, p=.018)$, the only statistically significant difference was in levels of affection toward IT $(p<0.05)$.

\section{Discussion and Conclusion}

According to the findings of this study, the participants showed positive attitudes toward the use of IT. It could be attributed to the home computer ownership among students, which may have contributed their IT attitudes in a positive direction. This result is compatible with the findings of the studies done by Tıngoy and Gulluoglu (2011); Wong and Hanafi (2007); Tuncer, Dogan, \&Tanas 
(2013); Yusuf and Balogun (2011), Al-Harby (2012); Yalman and Tunga (2014); they all found the same result, but this is inconsistent with Shunnaq and Domi (2010) who found that students held positive attitudes before employing E-learning in class and their attitude changed to negative after employing E-learning in class.

The purpose of this study was to determine the relationship between students' attitudes towards IT and their academic achievement according to students' disciplines. The study found a statistically significant difference between Arts and Science students in their attitude towards IT, in favor of Science students. This finding is consistent with the previous literature (Abdulhamed, 2005; Abul-Ela \& Shezawi, 2004; Subramani, 2012); they have found the same result, while it was inconsistent with some others (Abdelaziz, Jamaluddin, \& Leng, 2013) which indicated no significant differences between participants' attitudes toward the Internet and computer related with field of study. This may suggest that the Science field students are more experienced in using IT due to their course materials that require them to use it.

The study also found no significant difference between Art and Science students in terms of their affection towards IT, as well as the differences between the two groups in terms of their belief towards IT, while the differences between Arts and Science students in their behavior towards IT was found to be statistically significant in favor of Science students. The Science students appeared to be more confident in using computers and participating in the activities related to IT, they earned higher scores in the behavior component toward IT. Thus, students' behavior towards information technology appeared to be higher than their affection and belief towards IT; also students' affection appeared to be lower than their behavior, and beliefs towards IT. Hence, students' affection has the lowest dimension among the attitudinal components which refer to their feelings regarding the use of IT in their learning. This finding is inconsistent with Muslim (2010) study which found that the cognitive, emotional and behavioral attitudes scores increased significantly after the students' exposure to computer use. This may suggest that the students are less motivated and have no tendencies and interests in learning at Koya University.

Furthermore, when the relationship between students' attitude towards IT, and their academic achievement was tested, there proved to be no statistically significant relationship between them. This finding was inconsistent with the studies that found a significant relationship between students' attitude towards IT and their academic achievement such as Ilgan (2013); Taylor and Duran (2006); Schroeder et al. (2007); Juma and Ahmed (2012); Skryabin, Zhang, Liu, and Zhang (2015); Akpinar et al. (2009), while it was compatible with the previous studies such as Shieh, Chang \& Liu (2011); Lei (2010); Aljabri (2012)) who found no statistically significant relationship students' attitude towards IT and their academic achievement. It could be concluded that students have used IT more for communications and entertainment itself, not to fulfil the aim of the learning process, they are busier with the social network such as Facebook, YouTube, and others, instead of using the Internet to do research (rarely), downloading electronic resources, and launching into e-mail communications; whereas university which does not offer Internet connection to them and they are usually self-sponsored.

Additional result of the current study found that there is a statistically significant difference between students' achievement grades in their affection towards IT. The independent sample ttest was performed comparing the satisfactory (50-59) and medium (60-69) grades of students' 
academic achievement on the attitude towards IT scale; students at the medium level of academic achievement had demonstrated higher affection towards IT than students at the satisfactory level of the academic achievement. The result indicated little evidence that students with high affection towards IT tend to score higher grades in their exams. Therefore, the findings of this current study hold some implications for policy makers to pay attention to the students and facilitate certain conditions in order to encourage students to use IT in their learning by enhancing their affection and beliefs towards using IT. In the meantime, Cocorada and Palasan (2014) stated that a favorable attitude towards computer use in learning and in everyday life is a condition of obtaining high performance in learning and later in the workplace.

In conclusion, the findings of this study provide evidence of students' attitude toward IT and their academic achievement, and contribute to our understanding of students' low achievement at Koya University, which was related to their feelings and tendencies towards learning.

The findings of this study reveal that students had positive attitudes towards IT. When the underlying dimensions of the attitude towards IT were measured via the PCA, there appeared to be three dimensions for attitudes towards IT scale which were affection, behavior, and cognition. The behavior component recorded the higher score compared with the affection and belief components, also the affection component appeared to be the lowest among all the attitude components. When the differences between the two groups of Arts and Science of students were tested via one independent sample t-test, there proved to be a statistically significant difference between Arts and Science students in their attitude towards IT, which was shown to be in favor of Science students. Furthermore, when the relationship between students' attitude towards IT, and their academic achievement was tested via correlations, there proved to be no statistically significant relationship between them. A set of independent samples t-tests was performed comparing the satisfactory (50-59) and medium (60-69) grades of students' academic achievement on the attitude scale, students at the medium level of academic achievement had demonstrated higher affection towards IT than students at the satisfactory level of the achievement.

\section{Limitations of the Study}

There are several limitations that need to be acknowledged within this study. While examining the relationships between students' attitudes towards IT and their academic achievement, the study is subject to the following limitations.

First, in this study the data were only collected at Koya University in Iraq, and students' attitude towards IT (AITQ), serve as the survey instruments of the study. This study was conducted in public universities only however the private Universities were not included. In this case, the findings of this study cannot be generalized on the private universities due to the different environment and situation. Moreover, this study determines students' academic achievement level and scores at Koya University, while other university students' academic achievements were not included. In this study, it should be noted that the non-significant correlations between the attitude towards IT and their academic achievement may have been due to the students' year of study which only included the second and fourth year students. 


\section{Recommendations for Future Research}

The following recommendations for further research have been set based on the results and conclusions of this study.

- Further studies using the quantitative and qualitative approaches to find out the relationship between students' attitude towards IT with their academic achievement are necessitated to draw several implications.

- The students' motivation issue was not addressed in this study; it would be beneficial to investigate students' motivation in their learning through interview or survey. Student motivation would provide another data source to support the improvement of their academic achievement.

- Future researchers could expand this research by determining the undergraduate students' attitude towards IT and the relationship with their academic achievement in all public universities in Iraq.

- Moreover, all these statistical data should be supported by extended qualitative studies to provide a deeper understanding of students' attitude towards IT and the relationship with their academic achievement.

- This study has investigated the differences between the field of study (Arts and Science) in terms of attitude towards IT, future research may focus on the other factors like gender as well as computer and Internet experience.

\section{References}

Abdulhamed, I. S. (2005). Students attitudes toward the use of Internet and the relationship with their academic achievement: A comparative study between the gender. Retrieved on 24 December 2013 from http: //psychology-egypt.150m.com/internetAtt.stud.htm

Abedalaziz, N., Jamaluddin, S., \& Leng, C. H. (2013). Measuring attitudes toward computer and Internet usage among postgraduate students in Malaysia. Turkish Online Journal of Educational Technology, 12(2), 200-216.

Abul-Ela, M. R. A. \& Shezawi, A. G. B. M. (2004). Internet self-efficacy, attitude toward Internet and self-directed learning skills among students in School of Education in Sohar (Oman). Arab Bureau of Education for the Gulf States. Retrieved on 12 March 2013 from http://www. abegs. org/sites/Research/default.aspx

Akpinar, E., Yildiz, E., Tatar, N., \& Ergin, O. (2009). Students' attitudes toward science and technology: An investigation of gender, grade level, and academic achievement. Procedia Social and Behavioral Sciences, 1, 2804-2808. 
Al Bataineh, M. \& Anderson, S. (2015). Jordanian social studies teachers' perceptions of competency needed for implementing technology in the classroom. Contemporary Educational Technology, 6(1), 38-61

Al-Harby, M. B. S. (2012). The attitudes of Saudi scholarships students to use the Internet in learning and their training needs required to use it. Information Studies, 12, 167-222.

Ali, Q. I. (2012, May). Information technology tools as a key for the development of educational institutions. Paper presented at the Engineering Education Conference. University of Duhok, Iraq.

Aljabri, N. M. R. (2012). The level of applications and the use of computer programs among the university students. Literature Faraaheedi, 12, 459-492.

Allport, G. (2001). The theoretical background of modern social psychology. In P. Erwin (Ed.), Attitude and persuasion. Abingdon, UK: Psychology Press.

Bawaneh, S. S. (2011). Information technology, accounting information system and their e ffects on the quality of accounting university education: An empirical research applied on Jordanian financial institutions. Interdisciplinary Journal of Contemporary Research in Business, 3(2), 1815-1840.

Christensen, R. \& Knezek, G. (1998). Teachers' attitudes toward computers questionnaire. Retrieved on 24 December 2013 from http://www.tcet.unt.edu/pubs/studies/index.htm

Cocorada, E. \& Palasan, T. (2014, April). Computer anxiety and computer self-efficacy for the high school students. Paper presented at the the 10th International Scientific Conference eLearning and Software for Education. Bucharest, Romania.

Eret, E., Gokmenoglu, T., \& Demir, C. E. (2013). A review of research on educational theories and approaches affecting students achievement: 1990-2011. Elementary Education Online, 12(3), 687-700.

Fabrigar, L. R., Wegener, D. T., MacCallum, R. C., \& Strahan, E. J. (1999). Evaluating the use of exploratory factor analysis in psychological research. Psychological Methods, 4(3), 272-299.

Gay, L. R. \& Airasian, P. (2003). Educational research: Competencies for analysis and applications. New York: Pearson.

Hair, J. F. Jr., Anderson, R. E., Tatham, R. L., \& Black, W. C. (1998). Multivariate data analysis (5th ed.). Upper Saddle River: NJ: Prentice-Hall.

Huskinson, T. L. H. \& Haddock, G. (2006). Individual differences in attitude structure and the accessibility of the affective and cognitive components of attitude. Social Cognition, 24 (4), 453-468. doi: 10.1521/soco.2006.24.4.453

Ilgan, A. (2013). Predicting college student achievement in science courses. Baltic Science Education and Scientific Research, 12(3), 322-336.

Inoue, Y. (2007). Technology and diversity in higher education new challenges. Hershey, PA: Information Science.

Jarrah, N. B. \& Ashour, W. A. S. (2009). Teachers' attitudes towards the use of computer as an educational tool In Iraqi schools. Maysan Magazine for Academic Studies, 8(5), 1-15. 
Juma, A. A. R. \& Ahmad, B. (2012). The effectiveness of teaching organic chemistry using the ((Web Quest)) strategy on the third stage students achievement in the Faculty of Sciences University of Sulaymaniyah. El Fath, 49, 62-97.

Kaiser, H.F. (1974). An index of factorial simplicity. Psychometrika, 39, 31-36.

Kompf, M. (2005). Information and communications technology (ICT) and the seduction of knowledge, teaching, and learning: What lies ahead for education. Curriculum Inquiry, 35(2), 213-234.

Lei, J. (2010). Quantity versus quality: A new approach to examine the relationship between technology use and student outcomes. British Journal of Educational Technology, 41(3), 455472. doi: 10.1111/j.1467-8535.2009.00961.x

Liu, E. Z.-F., Lee, C.-Y., \& Chen, J.-H. (2013). Developing a new computer game attitude scale for taiwanese early adolescents. Educational Technology \& Society, 16(1), 183-193.

Lukow, J. E. (2005). Students attitudes toward the use of technology in the classroom 1-3. Retrieved on 24 September 2013 from www.lsu.edu/departments/the/EProc05/Lukowedit.pdf

Muslim, I. M. (2010). The influence of CALL on students attitudes toward comprehension. College Of Education For Women, 21(3), 743-749.

Mustafa, K. I. (2005). Internet usage, self-efficacy and attitude among postgraduate students of International Islamic University Malysia (Unpublished doctoral dissertation). International Islamic University Malysia (IIUM).

Rob, E. M., Mary, T., \& Grainne, C. (2012). Student attitudes towards and use of ICT in course study, work and social activity: a technology acceptance model approach. British Journal of Educational Technology \& Society, 43(1), 71-84.

Safdar, M. R., Sher, F., Iqbal, S., Shakir, K. A., Ali, W., Sohail, M. M., \& Saeed, S. (2012). The role of information technology in education sector (A case study of Faisalabad - Pakistan). International Journal of Asian Social Science, 2(8), 1294-1299.

Samarrai, F. F. \& Rais, H. T. (2006). Evaluate the use of Internet as a technique of teaching and proposals developed - A field study sections of mathematics and computing. Journal of Diyala, 22, 55-69.

Schroeder, C. M., Scott, T. P., Tolson, H., Huang, T. Y., \& Lee, Y. H. (2007). A meta-analysis of national research: Effects of teaching strategies on student achievement in science in the United States. Journal of Research in Science Teaching, 44(10), 1436-1460.

Shieh, R. S., Chang, W., \& Liu, E. Z. F. (2011). Technology enabled active learning (TEAL) in introductory physics: Impact on genders and achievement levels. Australasian Journal of Educational Technology \& Society, 27(7), 1082-1099.

Shukakidze, B. (2013). The impact of family, school, and student factors on student achievement in reading in developed (Estonia) and developing (Azerbaijan) countries. International Education Studies, 6(7), 131-143. doi: 10.5539/ies.v6n7p131

Shunnaq, Q. M. \& Domi, H. A. A. B. (2010). Teachers and student's attitudes towards the use of elearning in secondary schools of Jordan. Damascus University Journal 26(1), 235-271. 
Skryabin, M., Zhang, J., Liu, L., \& Zhang, D. (2015). How the ICT development level and usage influence student achievement in reading, mathematics, and science. Computers \& Education, 85, 49-58.

Subrani,P.C.N. (2012). A study on attitude of arts and science college students towards using modern technology in class room instruction. Research Expo International Multidisciplinary Research Journal, 2(3), 83-86.

Taylor, A. J. \& Duran, M. (2006). Teaching social studies with technology: New research on collaborative approaches. The History Teacher, 40(1), 9-25.

Tingoy, O. \& Gulluoglu, S. S. (2011). Informatics education in different disciplines at university level case study: A survey of attitude toward information technology. The Turkish Online Journal of Educational Technology, 10(4), 221-229.

Tuncer, M., Dogan, Y., \& Tanas, R. (2013). Investigation of vocational high-school students' computer anxiety. Turkish Online Journal of Educational Technology, 12 (4), 90-05.

Volk, K., Yip, W.M., \& Lo, T.K. (2003). Hong Kong pupils' attitudes toward technology: The impact of design and technology programs. Journal of Technology Education, 15(1), 48-63.

Wong, S. L. \& Atan, H. (2007). Gender differences in attitudes towards information technology among Malaysian student teachers: A case study at Universiti Putra Malaysia. Educational Technology \& Society, 10(2), 158-169.

Yalman, M. \& Tunga, M. A. (2014). Examining the attitudes of students from state and foundation universities in Turkey towards the computer and www (world wide web). Education and Science, 39(137), 222-233.

Yusuf, M. O. \& Balogun, M. R. (2011). Student-teachers' competence and attitude towards information and communication technology: A case study in a Nigerian university. Contemporary Educational Technology, 2(1), 18-36.

Correspondence: Zhwan Dalshad Abdullah, School of Educational Studies, Universiti Sains Malaysia, Penang, Malaysia 